\title{
Analysis of Near Miss Cases as a Reflection of Emergency Obstetric Services and Need of Obstetric ICCU
}

\author{
Disha Vijay Sahijwani, Ajesh Desai, Vijay Kansara
}

\begin{abstract}
Objectives: World Health Organization (WHO) has defined near miss case as 'a woman presenting any life-threatening condition and surviving a complication that occurred during pregnancy, childbirth or within 42 days of termination of pregnancy'. This study aims to calculate near miss rate (NMR), maternal mortality rate (MMR), severe maternal outcome ratio, and near miss maternal death of our hospital. Indications of near miss events (NME) and their mortality index and the incidence of each organ dysfunction and its mortality index have been studied.
\end{abstract}

Design: A retrospective study of hospital records was done to complete proforma and summarize obstetric and perinatal events from April 2011 to October 2011 at Civil Hospital, Ahmedabad. Near miss events were identified according to criteria of organ dysfunction given by Mantel et al 1998 .

Results: Out of total 3, 242 live births, 97 NME occurred among which 27 expired. Thus, NMR and MMR of our hospital is 21.5 per 1,000 and 832.8 per 100,000 live births respectively. Severe maternal outcome ratio is $29.9(97 / 3242)$ and maternal mortality to near miss ratio is $1: 2.58$. Mortality index of our institute is $27.8 \%$ (27/97). 80.4\% patients developed NME before hospitalization. Severe-PIH was the most common cause of NME but carried a low mortality index of $5.8 \%$. Whereas, complicated cases of malaria and hepatitis $E$ had high mortality index of 75 and $38.8 \%$ respectively.

Conclusion: This study describes a relatively high mortality index and NMR (21.5/1,000 live births) as compared to data from other developing countries.

Keywords: Near miss case/rate, Maternal mortality rate, Severe maternal outcome ratio.

How to cite this article: Sahijwani DV, Desai A, Kansara V. Analysis of Near Miss Cases as a Reflection of Emergency Obstetric Services and Need of Obstetric ICCU. J South Asian Feder Obst Gynae 2013;5(3):99-101.

Source of support: Nil

Conflict of interest: None declared

\section{INTRODUCTION}

Maternal mortality is frequently described as 'just the tip of the iceberg', implying that there is a vast base to the iceberg maternal morbidity (Near Miss) - which remains largely undescribed. Stones et $\mathrm{al}^{3}$ were the first to use the term 'Nearmiss morbidity' to define a narrow category of morbidity related to 'Potentially life-threatening episodes'. Fitzpatrick et al used Samm (Severe acute maternal morbidity).

This study has been conducted to identify the characteristics of NME and assess the treatment received by them. This will help us to design future intervention in maternal health sector for reducing near miss rate and improve quality of care at hospital level which together will lead to reduction of mortality index and subsequently MMR.

\section{DEFINITIONS}

Near miss events (NME), were identified according to criteria given by Mantel et al $1998^{2}$ and NME is define as a lifethreatening event during pregnancy, labor or 42 days postpartum, irrespective of outcome (maternal death or survival).

Maternal near-miss (NM) is defined as 'a woman who nearly died but survived a complication that occurred during pregnancy, childbirth or within 42 days of termination of pregnancy'.

Maternal death (MD) is defined according to the tenth revision of International Classification of Diseases (ICD-10) by the WHO. ${ }^{1}$

Maternal mortality rate (MMR) is defined as the number of maternal deaths per 100,000 live births.

Maternal near miss rate (NMR) was calculated as number of maternal near miss per 1,000 live births. It indicates prevalence of near miss.

Severe maternal outcome ratio (SMOR) refers to the number of women with life-threatening complications per 1,000 live births $(\mathrm{LB}) . \mathrm{SMOR}=(\mathrm{NM}+\mathrm{MD}) / \mathrm{LB}$. It reflects the total morbidity.

Mortality index is defined as the number of maternal deaths resulting from a particular obstetric condition divided by the sum of the near-miss morbidities and maternal deaths occurring from such obstetric condition, expressed as a percentage $(\mathrm{MD} / \mathrm{MD}+\mathrm{NM})$. Mortality index is calculated to appreciate the standard of care provided for each complication.

Three different criteria have been used to identify near miss cases - disease specific, organ dysfunction and management based criteria.

Disease specific criteria given by Waterstone et al $2001^{4}$ include severe pre-eclampsia, eclampsia, HELLP syndrome, severe hemorrhage, severe sepsis and uterine rupture.

Management-based criteria given by Mantel et al $1998^{2}$ depends on availability and capacity of ICU and guidelines for ICU admission.

Organ system-based criteria given by Mantel et al $1998^{2}$ includes criteria for cardiac, vascular, immunological, respiratory, renal, liver, metabolic, coagulation and cerebral dysfunction are regarded as the most specific means of identifying near-misses. WHO has also given organ based dysfunction criteria in 2009.

These criteria may be tailored according to the appropriate setup to support diverse objectives, including monitoring progress, epidemiological surveillance and auditing of healthcare. 


\section{MATERIALS AND METHODS}

A retrospective study of women's medical records (3,242 cases) was done to complete proforma and summarize obstetric and perinatal events from April 2011 to October 2011 at Civil Hospital, Ahmedabad. Near miss events were identified according to criteria given by Mantel et al 1998. Cases of medical disorders like hepatitis E, malaria and anemia which lead to organ dysfunction were included.

Data collected included demographic characteristics, obstetric complication in current pregnancy, time of occurrence of event, place where primary treatment taken, transport used, organ dysfunction involved, method of delivery, outcomes (maternal and perinatal), treatment including special interventions done up to hospital discharge.

\section{RESULTS}

Out of total 3,242 live births, 97 NME occurred among which 27 expired (Table 1). Thus, NMR and maternal mortality rate of the study is 21.5 per 1,000 and 832.8 per 100,000 live births (LB) respectively. Severe maternal outcome ratio is 29.9

$(97 / 3242)$ and maternal mortality to near miss ratio is $1: 2.58$. Mortality index of our institute is $27.8 \%$ (27/97).

In this study, 78 out of 97 (80.4\%) patients developed NME before hospitalization. Twenty out of 78 patients died giving the mortality index of $25.6 \%$ for the NME developed before hospitalization compared to the mortality index of $36.8 \%$ for the NME developed during hospitalization (Table 2).

Severe-PIH was the most common cause of NME (36\%) but carried a low mortality index of $5.8 \%$. Whereas, complicated cases of malaria (4.3\%) and hepatitis E (18.5\%) had high mortality index of 75.0 and $38.8 \%$ respectively. Due to epidemic of hepatitis $\mathrm{E}$ in Gujarat during the study period and fulminant course of hepatitis $\mathrm{E}$, hepatitis $\mathrm{E}$ along with malaria and anemia led to $18.5 \%$ of NME. Mortality index of S. hemorrhage and sepsis were 29.6 and $28.7 \%$ respectively. No mortality occurred due to rupture uterus (Table 3 ).

The liver vascular and renal dysfunction accounted for 30.9, 27.8 and $15.4 \%$ of organ dysfunctions respectively. Patients with cardiac dysfunction (4.1\%) and respiratory dysfunction $(5.1 \%)$ were few.

Table 4 shows that mortality index of overt DIC is $100 \%$. The mortality index of immunological, Renal, cerebral and respiratory dysfunction is $50.0,46.6,42.8$ and $40 \%$ respectively. Low mortality index is found in cardiac (25\%), Liver (26.6\%) and vascular dysfunction (29.6\%).

\section{DISCUSSION}

The NMR of our institute (21.5) is lower than those of JP Souza et al (38), ${ }^{5}$ Almerie et al (32.9) ${ }^{6}$ and Abdel Azeim et al (22.1). ${ }^{7}$ However, their MMR (70.1, 54.8 and 432) and mortality index $(1.8,1.67$ and $19.5 \%)$ are much lower than our study MMR (832.8) and mortality index (27.8\%).

For every 2.5 women who survived NME, 1 expired. Thus, the MM to NM ratio of 1:2.5 of our study is much higher than that of JP Souza et $\mathrm{al}^{5}$ (1:54), Almerie et $\mathrm{al}^{6}$ (1:64) and Abdel Azeim et $\mathrm{al}^{7}$ (1:5.09). This comparison shows that peripheral health system should be strengthened to decrease the NMR and health services at our institute should be improved to decrease mortality index so that MMR can be reduced.

According to Almerie et al, ${ }^{6} 92.5 \%$ NME occurred before hospitalization which is similar to our study (80.4\%). Same was the case with the mortality index: MI of those who developed NME before hospitalization (1.06\%) was lower than

\begin{tabular}{|c|c|c|c|c|c|c|c|}
\hline $\begin{array}{c}\text { No. of } \\
\text { deliveries }\end{array}$ & $\begin{array}{c}\text { Total } \\
\text { near } \\
\text { miss events } \\
\text { (NME) }\end{array}$ & $\begin{array}{c}\text { Maternal } \\
\text { deaths }\end{array}$ & $\begin{array}{l}\text { Near } \\
\text { miss } \\
\text { rate* } \\
(\text { NMR) }\end{array}$ & $\begin{array}{c}\text { Maternal } \\
\text { mortality } \\
\text { rate** } \\
(M M R)\end{array}$ & $\begin{array}{c}\text { Severe } \\
\text { maternal } \\
\text { outcome } \\
\text { ratio*(SMOR) }\end{array}$ & $\begin{array}{l}\text { Maternal } \\
\text { mortality; } \\
\text { near miss }\end{array}$ & $\begin{array}{c}\text { Mortality } \\
\text { index } \\
(\%)\end{array}$ \\
\hline 3,242 & 97 & 27 & 21.5 & 832.8 & 29.9 & $1: 2.58$ & 27.8 \\
\hline
\end{tabular}

*Per 1,000 live births ** Per 1, 00,000 live births

\begin{tabular}{lccc}
\multicolumn{4}{c}{ Table 2: Comparison of onset of near miss event } \\
\hline & NME & MD & MI (\%) \\
\hline Before hospitalization & $78(80.4 \%)$ & $20(74.07 \%)$ & 25.6 \\
During hospitalization & $19(19.6 \%)$ & $7(25.92 \%)$ & 36.8 \\
\hline
\end{tabular}

Table 3: Indications of near miss and their outcome

\begin{tabular}{lcccc}
\hline & NME & MD & MI (\%) \\
\hline S.PIH & & $34(36 \%)$ & 2 & 5.8 \\
S.Hemorrhage & & $27(29 \%)$ & 8 & 29.6 \\
Sepsis & $7(7 \%)$ & 2 & 28.7 \\
Medical disorders & Hepatitis E & $18(18.5 \%)$ & 7 & 38.8 \\
& Malaria & $4(4.3 \%)$ & 3 & 75.0 \\
& Aplastic anemia & $3(3.3 \%)$ & 1 & 30.0 \\
Rupture & Other & $2(2.1 \%)$ & 0 & 0.0 \\
& & $1(1.1 \%)$ & 0 & 0.0 \\
\hline
\end{tabular}

Table 4: Incidence of various organ dysfunctions

\begin{tabular}{|c|c|c|c|c|}
\hline Organ involved & & NME & $M D$ & MI \\
\hline Cardiac & & $4(4.1 \%)$ & 1 & $25.0 \%$ \\
\hline Respiratory & & $6(6.1 \%)$ & 2 & $33.0 \%$ \\
\hline Renal & & $15(15.4 \%)$ & 7 & $46.6 \%$ \\
\hline Liver & & $30(30.9 \%)$ & 8 & $26.6 \%$ \\
\hline Cerebral & & $8(8.2 \%)$ & 3 & $37.5 \%$ \\
\hline \multirow[t]{2}{*}{ Coagulation } & Overt DIC & $1(7.2 \%)$ & 1 & $100 \%$ \\
\hline & Subclinical DIC & $6(6.2 \%)$ & 0 & $0.0 \%$ \\
\hline Vascular & & $27(27.8 \%)$ & 8 & $29.6 \%$ \\
\hline Immunological & & $8(8.2 \%)$ & 4 & $50.0 \%$ \\
\hline
\end{tabular}

Note: Many patients have more than one organ dysfunction thus leading to NME $>97$ and MD $>27$ in this table 
the mortality index of those who developed NME during hospitalization $(8.8 \%)$.

Because of causes like pulmonary embolism which have short onset to death duration, patients developing these die before reaching civil hospital. Hence, they are not counted in the NME and thus reduce the mortality index of NME developing before hospitalization.

According to a study from kidney hospital, ${ }^{8}$ incidence of pregnancy related ARF is $9 \%$ of 772 patients of renal failure in 2 years period. Thus, 15 patients of pregnancy related ARF are treated in 6 months similar to our study.

Maternal mortality according to the study at Institute of Kidney Diseases and Research Centre, Ahmedabad, was 18.6\% as opposed to our study in which renal dysfunction carries a mortality of $46.6 \%$. Majority of deaths with renal dysfunction have multiorgan failure so only renal dysfunction is not a root cause of death in these patients. So, mortality of $46.6 \%$ is not indicative of true mortality index of renal dysfunction.

Both hepatitis E and malaria are infectious diseases and largely preventable. Presence of epidemic of hepatitis E during study period resulted in $18.5 \%$ near miss cases. The fulminant course of viral hepatitis led to mortality index of $38 \%$. Proper implementation of health programs and chloroquine prophylaxis can help prevent development of life-threatening complications.

Liver, vascular and renal dysfunction accounted for 30.9, 27.8 and $15.4 \%$ of organ dysfunctions. More funds diverted for management of these dysfunctions can help to reduce NM events. High mortality index was found in cerebral dysfunction, respiratory, cardiac dysfunction. Thus, patients suffering from these can be given priority for ICU admission. Prompt admission in ICU may prevent multiple organ failure responsible for high mortality.

Criteria for ICU admission should be expanded beyond those requiring ventilator supports. Since, a single ICU cannot accommodate critical patients from all disciplines, obstetric ICU should be established.

\section{LIMITATIONS OF THE STUDY}

As large numbers of patients develop multiple organ dysfunctions, the organ dysfunction which led to maternal death cannot be evaluated. Thus, mortality index specific to organ dysfunction will not give true estimate of quality of care.

\section{CONCLUSION}

In current study late referrals, illiteracy, poverty and rural residence may be predictors of NME. Hence, the Maternal near miss rate (MNMR) which this study describes $(21.5 / 1,000$ live births) is more than the range of ratios reported in studies from other developing countries which used organ dysfunction criteria for near miss definition (3.8-10.9 per 1,000 deliveries). The study also describes a high mortality index of $27.8 \%$ (1:2.5) which indicates that for every 2.5 women who survived lifethreatening complications, one maternal death was recorded. This ratio, which reflects overall standard of obstetric care, is very high compared to studies from other developing countries (1:28 in Bolivia, 1:62 in Brazil, 1:15 in Benin, 1:18 in Cote d'Ivoire and far from the 1:117 to 223 ratios reported from Western Europe.

\section{REFERENCES}

1. Evaluating the quality of care for severe pregnancy complications: The WHO near-miss approach for maternal health. World Health Organization; 2011. Available at: http:// whqlibdoc. who.int/publications/2011/9789241502221_eng.pdf

2. Mantel GD, Buchmann E, Rees H, Pattinson RC. Severe acute maternal morbidity: a pilot study of a definition for a near-miss. Br J Obstet Gynaecol 1998;105:985-990.

3. Stones W, Lim W, Al-Azzawi F, Kelly M. An investigation of maternal morbidity with identification of life-threatening 'near miss' episodes. Health Trends 1991, 23:13-15.

4. Waterstone M, Bewley S, Wolfe C. Incidence and predictors of severe obstetric morbidity: case-control study. BMJ 2001; 322(7294):1089-1094.

5. Souza J, Cecatti JG, Parpinelli MA, Serruya SJ, Amaral E. Appropriate criteria for identification of near-miss maternal morbidity in tertiary care facilities: a cross-sectional study. BMC Pregnancy Childbirth 2007;7:20.

6. Almerie Y. Obstetric near-miss and maternal mortality in Maternity University Hospital, Damascus, Syria: a retrospective study. BMC Pregnancy Childbirth; 2010 Oct 19;10:65.

7. Ali AAA, Khojali A, Okud A, Adam GK, Adam I. Maternal near-miss in a rural hospital in Sudan. BMC Pregnancy and Childbirth 2011;11:4811-4848.

8. Goplani KR, Shah PR, Trivedi HL. Pregnancy-related acute renal failure: A single-center experience. Indian J Nephrol 2008 January;18(1):17-21.

\section{ABOUT THE AUTHORS Disha Vijay Sahijwani (Corresponding Author)}

Resident, Department of Obstetrics and Gynecology, Sola Civil Hospital GMERS, Sola, Gujarat, India, e-mail: dishavs_23@ hotmail.com

\section{Ajesh Desai}

Professor and Head, Department of Obstetrics and Gynecology GMERS Medical College, Sola, Gujarat, India

\section{Vijay Kansara}

Associate Professor, Department of Obstetrics and Gynecology GMERS Medical College, Sola, Gujarat, India 